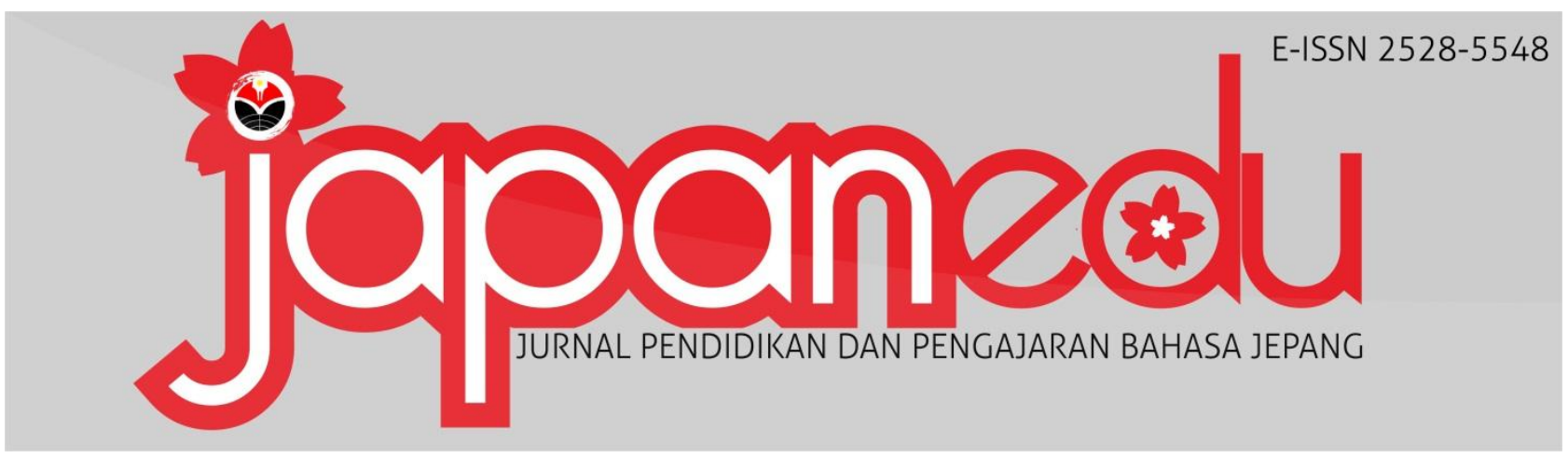

\title{
METODE MIND MAP DALAM MENINGKATKAN MINAT DAN KEMAMPUAN MEMBACA PEMAHAMAN BAHASA JEPANG TINGKAT DASAR
}

\author{
Atieka Sumaroh ${ }^{1}$, Neneng Sutjiati $^{1}$, Ahmad Dahidi $^{2}$ \\ ${ }^{1}$ Departemen Pendidikan Bahasa Jepang, Universitas Pendidikan Indonesia, \\ Jl. Dr. Setiabudhi No. 229, Bandung 40154, Indonesia
}

E-mail: atieka.sumaroh14@gmail.com

Telp: +62812-2345-6505

\begin{abstract}
Abstrak
Ada empat keterampilan berbahasa yang dipelajari, diantaranya adalah menyimak, membaca, menulis, dan berbicara. Untuk meningkatkan minat dan kemampuan membaca pemahaman pembelajar bahasa Jepang diperlukan metode dan cara pembelajaran yang unik dan menyenangkan. Perkembangan teknologi yang semakin pesat membuat tren minat membaca dikalangan pelajar khususnya mengalami penurunan. Dikarenakan pembelajar lebih memilih media internet dan sebagainya daripada membaca buku. Tujuan penelitian ini untuk mengetahui metode mind map dapat meningkatkan minat membaca dan kemampuan dalam memahami teks berbahasa Jepang. Penelitian ini dilakukan pada kelas XI IPA 8 SMA Negeri 1 Cirebon. Agar tumbuhnya minat untuk membaca teks bahasa Jepang, di perlukan metode pembelajaran yang tepat. Salah satu metode pembelajaran yang bisa digunakan dalam pembelajaran membaca pemahaman bahasa Jepang yaitu metode mind map. Penelitian ini tidak menggunakan kelas pembanding, hanya menggunakan satu kelas eksperimen dalam melakukan pengumpulan datanya, yang disebut dengan eksperimen semu. Adanya peningkatan hasil rata - rata yang diperoleh subjek penelitian setelah menggunakan metode mind map, dari 56,35 menjadi 73,38 yang berarti masuk dalam kategori cukup. Dapat disimpulkan jika taraf signifikansi $5 \%{ }^{t}$ hitung $=16,22,{ }^{t}$ tabel $=1,8$ maka hipotesis kerja (Hk) pada penelitian ini diterima.
\end{abstract}

Kata kunci: Mind Map, Minat, Membaca Pemahaman

\begin{tabular}{ll}
\hline Pendahuluan & bagi pembelajar bahasa. Untuk \\
Ada empat keterampilan berbahasa & meningkatkan minat dan kemampuan \\
diantaranya adalah menyimak (choukai), & membaca pemahaman pembelajar bahasa \\
membaca $($ dokkai), menulis (sakubun), dan & Jepang diperlukan metode dan cara \\
berbicara (kaiwa). Kemampuan membaca & pembelajaran yang unik dan menyenangkan. \\
pemahaman sangat penting untuk dipelajari & Diharapkan dengan adanya metode yang
\end{tabular}


menarik, siswa dapat meningkatkan minat dan kemampuan membaca pemahaman bahasa Jepang. Salah satu metode pembelajaran yang bisa digunakan dalam pembelajaran membaca pemahaman bahasa Jepang yaitu metode mind map. Metode pembelajaran Mind Map ini diharapkan dapat membantu pengajar dalam pembelajaran dan lebih mudah dipahami oleh siswa sehingga pembelajaran dapat berlangsung lebih menyenangkan. (Buzan, 2008 hlm 3) Mind map adalah hasil dari metode Mind mapping yang berupa hasil visualisasi yang berupa symbol atau gambar yang dapat digunakan sebagai ganti catatan tertulis dan hasilnya lebih cepat untuk diingat. Haruhiko dalam Puspita (2012 hlm 12) Membaca adalah melihat kata, kalimat, dan gambar yang ditulis dengan huruf kemudian memahami artinya. Minat yang ada pada diri siswa yang membuat siswa ingin membaca, terlebih lagi membaca dan memahami isi teks bahasa Jepang yang sulit dilakukan oleh siswa. Agar tumbuhnya minat untuk membaca teks bahasa Jepang, di perlukan metode pembelajaran yang tepat. Berdasarkan latar belakang penelitian yang telah dijelaskan diatas, peneliti bermaksud mengadakan penelitian yang berjudul metode mind map dalam meningkatkan minat dan kemampuan membaca pemahaman bahasa jepang tingkat dasar. Penelitian ini bertujuan; 1) Untuk mengetahui minat yang dimiliki siswa dalam pembelajaran bahasa Jepang, 2) Untuk mengetahui kemampuan siswa dalam membaca pemahaman teks dalam bahasa Jepang. 3) Untuk mengetahui metode mind map dapat meningkatkan minat siswa membaca teks dalam bahasa Jepang. 4) Untuk mengetahui metode mind map dapat meningkatkan kemampuan siswa dalam membaca pemahaman teks dalam bahasa Jepang.

\section{Metode Penelitian}

Penelitian ini menggunakan metode eksperimen dengan menggunakan desain pre-test and post-test design. Penelitian ini tidak menggunakan kelas pembanding, hanya menggunakan satu kelas eksperimen dalam melakukan pengumpulan datanya, yang sering disebut dengan quasi experiment atau eksperimen semu.

Menurut Sutedi (2011 hlm 179), manusia yang dijadikan sebagai sumber data penelitian disebut dengan papulasi penelitian. Populasi dari penelitian ini adalah siswa SMA NEGERI 1 KOTA CIREBON.

\section{Temuan dan Pembahasan}

Dari hasil perhitungan data pre-test dan post-test, didapatkan hasil thitung 16,22 dan tabel 1,8 dengan taraf signifikansi $5 \%$ yang berarti thitung lebih besar dari tabel. Maka hipotesis kerja (Hk) pada penelitian ini diterima. Pengolahan data angket dilakukan dengan cara menjumlahkan setiap jawaban angket kemudian menghitung persentase frekuensi per jawaban dengan menggunakan rumus berikut :

$$
\mathrm{P}=\frac{f}{n} \mathrm{X} 100 \%
$$

Interpretasi hasil pengolahan data kuesioner :

\begin{tabular}{|c|c|}
\hline Persentase & Keterangan \\
\hline $0,00 \%$ & Tak seorangpun \\
\hline $01,00 \%-05,00 \%$ & Hampir tidak ada \\
\hline $06,00 \%-25,00 \%$ & Sebagian kecil \\
\hline $26,00 \%-49,00 \%$ & Hampir setengahnya \\
\hline $50,00 \%$ & Setengahnya \\
\hline $51,00 \%-75,00 \%$ & Lebih dari setengahnya \\
\hline $76,00 \%-95,00 \%$ & Sebagian besar \\
\hline $96,00 \%-99,00 \%$ & Hampir seluruhnya \\
\hline $100 \%$ & Seluruhnya \\
\hline
\end{tabular}




\section{Kesimpulan}

Berdasarkan hasil data yang telah diolah dan diuji hipotesisnya, dapat disimpulkan sebagai berikut :

1. Adanya peningkatan hasil rata - rata yang diperoleh subjek penelitian setelah menggunakan metode mind map, dari 56,35 menjadi 73,38 yang berarti masuk dalam kategori cukup.

2. Nilai hitung $=16,22$ dan dibandingkan dengan derajat kebebasan (db) atau degree of freedom $(\mathrm{df})=36$ pada taraf signifikansi $5 \% \mathrm{t}_{\text {tabel }}=1,8$. Dapat disimpulkan jika taraf signifikansi 5\% ${ }^{\mathrm{t}}$ hitung $=16,22>{ }^{\mathrm{t}}$ tabel $=1,8$ maka hipotesis kerja (Hk) pada penelitian ini diterima. membuktikan bahwa adanya perubahan pada kemampuan siswa setelah menggunakan metode mind map.
3. Pada hasil angket minat membaca adanya ketertarikan sampel dalam membaca pemahaman teks berbahasa Jepang. Namun terkendala pada jenis buku dan tema pada bacaan. Sampel lebih memilih teks bacaan pada buku pelajaran dan tema yang menarik.

\section{Referensi}

[1] Buzan, Tony. 2008. Buku Pintar Mind Map. Jakarta. Gramedia Pustaka Utama.

[2] Puspita Sari, Rita. 2012. Kemampuan Pemahaman Siswa Dalam Pelajaran Membaca Dengan Menggunakan Metode Index Card Match. Skripsi. UPI Bandung: Tidak Diterbitkan.

[3] Sutedi, Dedi. 2011. Penelitian Pendidikan Bahasa Jepang. Bandung. Humaniora. 